DOI: https://doi.org/10.24867/16EF10Savic

\title{
EFIKASNOST ADSORPCIONOG UKLANJANJA ORGANSKIH POLUTANATA IZ EFLUENTA OFSET ŠTAMPE PRIMENOM NANOMATERIJALA
}

\section{THE EFFICIENCY OF ADSORPTION REMOVAL OF ORGANIC POLLUTANTS FROM OFFSET PRINTING EFFLUENT USING NANOMATERIALS}

\author{
Katarina Savić, Savka Adamović, Fakultet tehničkih nauka, Novi Sad
}

\begin{abstract}
Oblast - GRAFIČKO INŽENJERSTVO I DIZAJN
Kratak sadržaj - U radu je procenjena efikasnost adsorpcionog tretmana sa nanomaterijalom za smanjenje organskog opterećenja otpadnog ofset sredstva za vlaženje. Efikasnost tretmana adsorpcije utvrđena je na osnovu smanjenja koncentracije ukupnog organskog ugljenika iz ofset efluenta sa odgovarajućom dozom nanomaterijala. Za određivanje mehanizma adsorpcije ispitivanih adsorpcionih sistema primenjeni su kinetički modeli adsorpcije pseudo-prvog i pseudo-drugog reda.
\end{abstract}

Ključne reči: Ofset proces štampe, Adsorpcija, Nanomaterijal, Organsko jedinjenje, Efluent

\begin{abstract}
The efficiency of adsorption treatment with nanomaterial for reducing the organic load of waste offset fountain solution was evaluated in the paper. The efficiency of the adsorption treatment has been determined based on reducing the concentration of total organic carbon from the offset effluent with the appropriate dose of nanomaterials. Furthermore, the kinetic adsorption models of pseudo-first and pseudosecond order were applied to determine the adsorption mechanisms of the examined adsorption systems.
\end{abstract}

Keywords: Offset printing process, Adsorption, Nanomaterial, Organic compound, Effluent

\section{UVOD}

Industrijsko zagađenje životne sredine je isključivo antropogenog porekla i predstavlja veliki problem savremenog čoveka. Tako grafička industrija generiše otpadne vode koje su prisutne u konvencionalnoj pripremi štamparskih formi, u procesu ofset štampe (otpadni razvijač i otpadno sredstvo za vlaženje), kao i pri čišćenju mašina i opreme za štampu [1].

U konvencionalnoj ofset štampi sredstvo za vlaženje ima važne uloge jer uklanja i sprečava zadržavanje grafičke boje na neštampajućim elementima štamparske forme, usporava trošenje forme zbog trenja i produžava njen vek trajanja i sprečava taloženje osušene boje i papirne prašine na gumenoj navlaci. Da bi navedene uloge sredstva za vlaženje bile ostvarene, potreban je adekvatan kontakt sredstva za vlaženje i štamparske forme [2,3]. Usled kontakta sa štamparskom formom, ali i sa grafičkim

\section{NAPOMENA:}

Ovaj rad proistekao je iz master rada čiji mentor je bila dr Savka Adamović, docent. bojama i podlogom za štampu, sredstvo za vlaženje menja svoj hemijski sastav i kontaminira se neorganskim i organskim zagađujućim materijama. Postizanjem odgovarajućeg organskog i neorganskog opterećenja sredstvo za vlaženje se transformiše u efluent, odnosno otpadno sredstvo za vlaženje [1].

Razlog mnogobrojnih problema u kovencionalnoj ofset tehnici je prouzrokovan upravo neadekvatnim sastavom sredstva za vlaženje koje zavisi od tipa i kvaliteta vode, tipa štamparske mašine i sistema za vlaženje [3]. Sa druge strane, jedan od mnogobrojnih razloga zagađenja životne sredine je i ispuštanje štampom generisanog ofset efluenta sa potencijalno negativnim organskim i neorganskim opterećenjem [1]. Zadatak prečišćavanja ofset efluenta je da se ukloni neorgansko i organsko opterećenje do te mere da otpadna voda može ponovo da se upotrebi ili da se ispusti u prirodni recipijent ili kanalizacioni sistem bez štetnih posledica. To se ostvaruje primenom jednog ili više postupaka čija priroda može da bude fizička, hemijska i biološka.

Adsorpcija je hemijski postupak koji se komercijalno primenjuje za prečišćavanje otpadnih voda, jer je jedan od najboljih tretmana za smanjenje koncentracije neorganskih i organskih polutanata iz industrijskih efluenata. Utvrđeno je da je adsorpcija superiorna $u$ odnosu na druge postupke za prečišavanje otpadnih voda jer poseduje karakteristike poput: niskih troškova, jednostavnosti, kompatibilnosti sa životnom sredinom, netoksičnosti, hemijske stabilnosti, itd. Takođe, prednost adsorpcije je i upotreba širokog spektra prirodnih, sintetičkih i biomaterijala, kao adsorbenata [1].

$\mathrm{U}$ radu je primenjen adsorpcioni tretman sa nanomaterijalom za smanjenje organskog opterećenja ofset efluenta. Na osnovu smanjenja koncentracije ukupnog organskog ugljenika iz ofset efluenta sa odgovarajućom dozom nanomaterijala definisana je efikasnost tretmana adsorpcije. Primenom kinetičkih modela adsorpcije pseudo-prvog i pseudo-drugog reda utvrđen je mehanizam adsorpcije.

\section{EKSPERIMENTALNI DEO}

2.1. Karakterizacija sastava organskog opterećenja otpadnog ofset sredstva za vlaženje

Kvalitativno organsko optererećenje otpadnog ofset sredstva za vlaženje (OOSV) definisano je kroz tri faze:

1. pripremu uzorka sa tečno/tečnom ektrakcijom sa metilen-hloridom i sekvencijalnom ekstrakcijom 
sa n-pentanom, metilen-hloridom i metilenhloridom pri $\mathrm{pH}$ vrednosti 2 ,

2. kvalitativnu GC/MS (gasno hromatografsko/ maseno spektrometrijsku) analizu i

3. upotrebu softvera: za dekonvoluciju, automatizovanog masenog spektralnog softvera za dekonvoluciju i identifikaciju (AMDIS) i referentnog spektra baze podataka Nacionalnog instituta za standarde i tehnologiju (NIST) u cilju dodatne, preciznije identifikacije. ogranskih jedinjenja $u$ ofset efluentu OOSV sa verovatnoćom prisustva većom od $80 \%$.

Kvantitativno organsko opterećenje OOSV procenjeno je na osnovu sadržaja ukupnog organskog ugljenika (UOU ili engl., Total Organic Carbon, TOC). Prema standardnoj metodi SRPS ISO 8245:2007 uzorak OOSV je filtriran preko $0,45 \mu \mathrm{m}$ membranskog filtera. Nakon filtracije uzorka ofset efluenta, vrednosti UOU su određene primenom Likui TocII analizatora (Elementar, Nemačka) u skladu sa navedenom standardnom metodom [4].

\subsection{Adsorpcioni tretman otpadnog sredstva za vlaženje sa nanomaterijalom}

\subsubsection{Karakterizacija nanomaterijala}

U adsorpcionom tretmanu OOSV za nanomaterijal upotrebljene su višeslojne ugljenične nanocevi modifikovane oksidacijom tj. nagrizanjem sa koncentrovanom azotnom kiselinom. Izgled nanomaterijala analiziran je primenom transmisiono elektronske mikroskopije (slika 1).

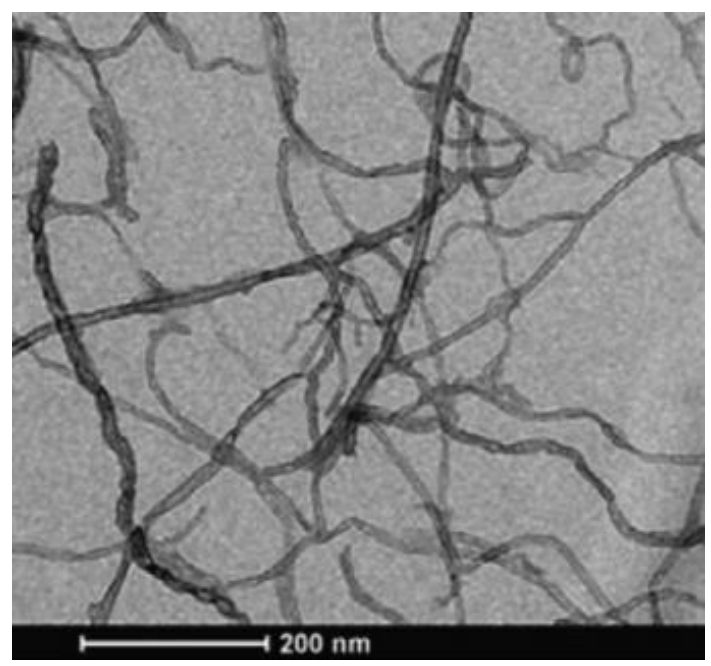

Slika 1. Nanomaterijal [5]

\subsubsection{Procedura adsorpcionog tretmana}

Za adsorpcioni tretman vodenoj suspenziji određene doze nanomaterijala $\left(0,5,1,1,5 \mathrm{i} 2,5 \mathrm{~g} \mathrm{~L}^{-1}\right)$ dodato je $15 \mathrm{~mL}$ ofset efluenta. Kiveta sa smešom nanomaterijala i OOSV je podvrgnuta kontinualnom mešanju na mešalici pri brzini od $150 \mathrm{rpm}$. Za svaku dozu nanomaterijala pripremljeno je 8 kiveta, a svaka od njih je kontinualno mešana u vremenima od: $1,3,5,15,30,45,60$ i 90 minuta.

Takođe, za ispitivane doze nanomaterijala, vreme potrebno za uspostavljanje adsorpcione ravnoteže za OOSV je određeno na osnovu preliminarnih eksperimenata kinetike za vremena od 5, 15, 30, 60, 120, 360, 1440 i 2880 minuta.
Nakon određenog vremenskog intervala kontakta adsorbenta (nanomaterijala) i adsorbata (OOSV), smeše su filtrirane kroz celulozno-nitratne membranske filtere (Sartorius Stedim Biotech $\mathrm{GmbH}$, Nemačka) veličine pora od $0,45 \mu \mathrm{m}$.

Dobijeni filtrat je zakišeljen do $\mathrm{pH}$ vrednosti 2 sa koncentrovanom $\mathrm{HCl}$ (35\%, p.a., Merck, Nemačka) i pripremljen za analizu sadržaja UOU.

\subsubsection{Efikasnost adsorpcionog tretmana}

Efikasnosti adsorpcionog uklanjana organskih supstanci iz OOSV sa nanomaterijalom određena je na osnovu smanjenja konventracije UOU primenom jednačine (1):

$$
E_{N}(\%)=\frac{C_{U O U o}-C_{U O U t}}{C_{U O U o}} \cdot 100
$$

gde su: $E_{N}$ - efikasnost uklanjanja (\%) UOU iz OOSV primenom nanomaterijala, $C_{U O U o}$ - inicijalna koncentracija $\left(2700 \mathrm{mg} \mathrm{L}^{-1}\right)$ UOU u OOSV pre adsorpcionog tretmana, $C_{\text {UOUt }}$ - koncentracija $\left(\mathrm{mg} \mathrm{L}^{-1}\right)$ UOU u OOSV posle adsorpcionog tretmana sa odgovarajućom dozom nanomaterijala $\mathrm{u}$ određenom vremenu kontakta nanonaterijala i OOSV.

\subsubsection{Matematičko-kinetički modeli adsorpcije}

Matematičko-kinetički model adsorpcije pseudo-prvog reda je linearnog oblika $(y=A+B x)$ i predstavljen je jednačinom (2):

$$
\ln \left(q_{e}-q_{t}\right)=\ln q_{e}-k_{l} \cdot t
$$

gde su: $q_{t}\left(\mathrm{mg} \mathrm{g}^{-1}\right)$ - adsorpcioni kapacitet $\mathrm{u}$ datom vremenu $t, q_{e}\left(\mathrm{mg} \mathrm{g}^{-1}\right)$ - adsorpcioni kapacitet $\mathrm{u}$ ravnoteži i $k_{l}\left(\min ^{-1}\right)$ - konstanta brzine adsorpcionog procesa pseudo-prvog reda.

$\mathrm{Za}$ matematičko-kinetički model adsorpcije pseudodrugog reda linearna jednačina (3) glasi:

$$
\frac{t}{q_{t}}=\frac{1}{k_{2} \cdot q_{e}}+\frac{1}{q_{e}} \cdot t
$$

gde su: $q_{t}\left(\mathrm{mg} \mathrm{g}^{-1}\right)$ - adsorpcioni kapacitet $\mathrm{u}$ datom vremenu $t, q_{e}\left(\mathrm{mg} \mathrm{g}^{-1}\right)$ - adsorpcioni kapacitet u ravnoteži, $k_{2}\left(\mathrm{~g} \mathrm{mg}^{-1} \mathrm{~min}^{-1}\right)$ - konstanta brzine adsorpcionog procesa pseudo-drugog reda.

Za obradu eksperimentalnih podataka odgovarajućeg kinetičkog modela adsorpcije upotrebljen je program Origin6.1 (OriginLab Corporation, SAD).

Na sve eksperimentalno dobijene vrednosti, primenjeno je linearno „fitovanje”, jer su oba reakciona modela adsorpcije data $u$ formi linearne jednačine.

$\mathrm{Na}$ osnovu koeficijenta determinacije $\left(R^{2}\right)$, koji predstavlja meru slaganja eksperimentalnih podataka sa primenjenim kinetičkim modelima adsorpcije, odabran je kinetički model koji bolje opisuje mehanizam adsorpcije, odnosno promenu koncentracije organskih supstanci iz OOSV tokom adsorpcije na nanomaterijalu. 


\section{REZULTATI I DISKUSIJA}

\subsection{Efikasnost adsorpcionog tretmana sa nanomaterijalom}

Kvalitativnom i kvantitativnom analizom organskog opterećenja OOSV utvrđeno je prisustvo 51. organske supstance čija inicijalna vrednost UOU $\left(C_{\text {UOUo }}\right)$ iznosi $2700 \mathrm{mg} \mathrm{L}^{-1}$. Detektovana organska jedinjenja pripadaju: višim alkanima, alkenima, policikličnim aromatičnim ugljovodonicima, alkoholima, etrima, ketonima, supstituisanim benzenima i derivatima benzena, organskim kiselinama i njihovim amidima i estrima, kao i organoazotnim jedinjenjima i organskim jedinjenjima sa azotom i kiseonikom.

Dobijeni rezultati adsorpcije UOU iz OOSV za različite doze nanomaterijala pokazuju da sa povećavanjem vremena kontakta od 1. do 2880. minuta efikasnosti adsorpcije rastu. Kako se doza povećavala 0,5 do $2,5 \mathrm{~g} \mathrm{~L}^{-1}$ efikasnosti su se povećavale od 31, 43, 61 i $62 \%$, redom. Takođe, za sve doze utvrđeno ravnotežno vreme adsorpcije od 360 minuta (slika 2). Kako su vrednosti efikasnosti uklanjanja UOU za doze nanomaterijala od 1,5 i $2,5 \mathrm{~g} \mathrm{~L}^{-1}$ bliske iz ekonomskih razloga odabrana je doza od $\quad 1,5 \mathrm{~g} \mathrm{~L}^{-1}$.

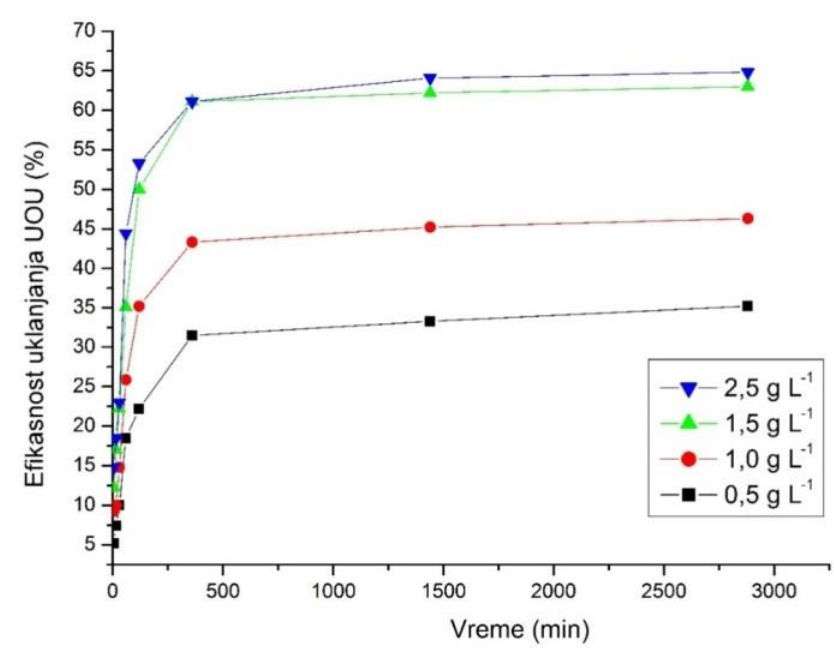

Slika 2. Određivanje ravnotežnog vremena za ispitivane doze nanaomaterijala

Efikasnosti uklanjanja organskih supstanci iz OOSV primenom adsorpcionog tretmana na nanomaterijalu za dozu $1,5 \mathrm{~g} \mathrm{~L}^{-1}$ i za vremena kontakta od 1. do 90. minuta prikazani su u tabeli 1 .

Tabela 1. Efikasnosti uklanjanja UOU iz OOSV za dozu nanomaterijala od $1,5 \mathrm{~g} \mathrm{~L}^{-1}$

\begin{tabular}{|c|c|c|}
\hline $\begin{array}{c}\boldsymbol{t} \\
(\mathbf{m i n})\end{array}$ & $\begin{array}{c}\boldsymbol{C}_{\text {UoUt }} \\
\left(\mathbf{m g ~ L}^{-\mathbf{1}}\right)\end{array}$ & $\begin{array}{c}\boldsymbol{E}_{\boldsymbol{N}} \\
(\boldsymbol{\%})\end{array}$ \\
\hline $\mathbf{1}$ & 2380 & 11,9 \\
\hline $\mathbf{3}$ & 2220 & 17,8 \\
\hline $\mathbf{5}$ & 2100 & 22,2 \\
\hline $\mathbf{1 5}$ & 1900 & 29,6 \\
\hline $\mathbf{3 0}$ & 1740 & 35,6 \\
\hline $\mathbf{4 5}$ & 1300 & 51,9 \\
\hline $\mathbf{6 0}$ & 1250 & 53,7 \\
\hline $\mathbf{9 0}$ & 1200 & 55,6 \\
\hline
\end{tabular}

Dobijeni rezultati pokazuju da sa povećavanjem vremena kontakta nanomaterijala i OOSV od 1. do 90. minuta vrednosti koncentracija UOU $\left(C_{U O U t}\right) \mathrm{u}$ ofset efluentu tokom adsorpcionog tretmana opadaju $\mathrm{u}$ interval od 2380 do $1200 \mathrm{mg} \mathrm{L}^{-1}$. Efikasnosti uklanjanja UOU iz OOSV sa povećavanjem vremena kontakta adsorbat/adsorbent rastu u nizu od 11,9 do 55,6\% (tabela 1). Dakle, u 90. minutu efikasnost uklanjanja UOU iz OOSV u odnosu na 1 . minut je viša 78,6\%. Kako je iz ekonomskih razloga opravdano izabrati manju dozu nanomaterijala, za optimalno vreme adsorpcije uzima se 45 minuta, jer se za još 15 minuta (u 60. minutu) efikasnost $(53,7 \%)$ povećala $3,4 \%$, a za dodatnih 45 minuta (u 90 . minutu) samo $6,5 \%$.

\subsection{Mehanizam adsorpcionog vezivanja organskih supstanci na nanomaterijalu}

$\mathrm{Na}$ osnovu linearne jednačine (2) za matematičkokinetički model adsorpcije pseudo-prvog reda, parametri zavisnosti modela su: $\ln \left(\mathrm{q}_{\mathrm{e}}-\mathrm{q}_{\mathrm{t}}\right)=f(\mathrm{t})$. Za matematičkokinetički model adsorpcije pseudo-drugog reda na osnovu linearne jednačine (3), parametri zavisnosti model su: $t / q_{t}$ $=f(\mathrm{t})$.

Grafički prikazi linearnog „fitovanja” matematičkokinetičkih modela adsorpcije pseudo-prvog i pseudodrugog reda prikazani su na slikama 3 i 4 , redom.

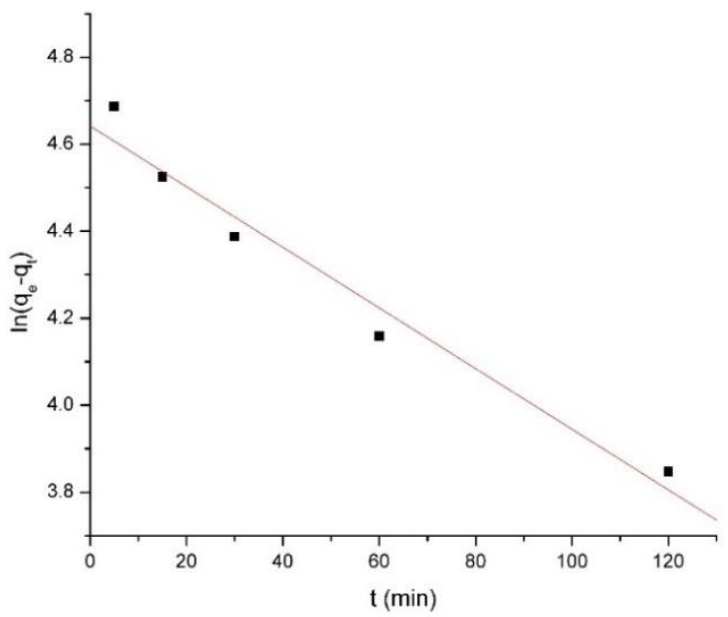

Slika 3. Linearno „fitovanje” za matematičko-kinetički model adsorpcije pseudo-prvog reda za uklanjanje organskih supstanci iz OOSV primenom nanomaterijala

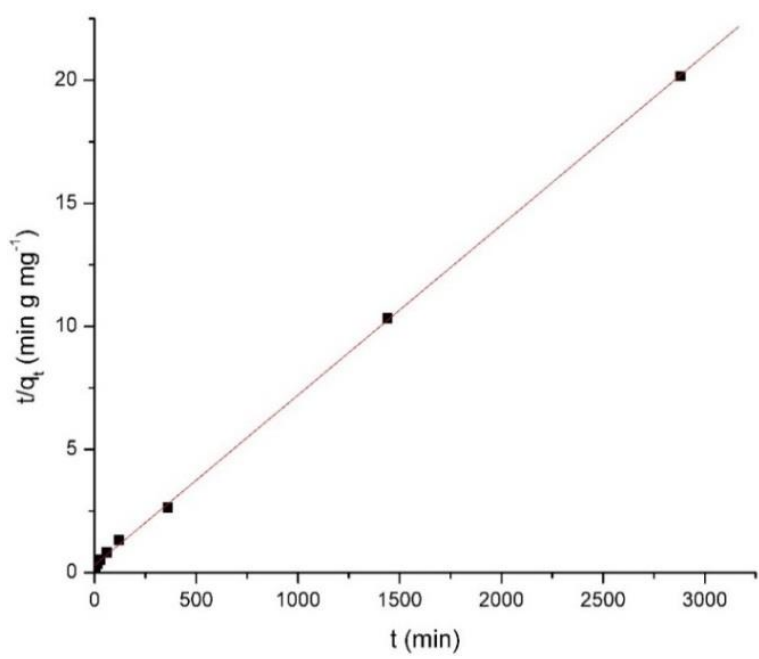

Slika 4. Linearno ,fitovanje” za matematičko-kinetički model adsorpcije pseudo-drugog reda za uklanjanje organskih supstanci iz OOSV primenom nanomaterijala 
Za matematičko-kinetičke modele adsorpcije pseudoprvog i pseudo-drugog reda parametri: konstante brzine $\left(k_{1}\right.$ i $\left.k_{2}\right)$ i adsorpcioni kapaciteti $\left(q_{e}\right)$, kao i koeficijenti determinacije $\left(R^{2}\right)$ za uklanjanja UOU iz OOSV primenom nanomaterijala prikazani su u tabeli 2 .

Tabela 2. Parametri matematičko-kinetičkih modela adsorpcije pseudo-prvog i pseudo-drugog reda za uklanjanje organskih supstanci iz OOSV primenom nanomaterijala

\begin{tabular}{|c|c|c|}
\hline Kinetički model & Parametar & Vrednost \\
\hline \multirow{2}{*}{$\begin{array}{c}\text { Pseudo-prvog } \\
\text { reda }\end{array}$} & $k_{l}\left(\mathrm{~min}^{-1}\right)$ & 0,01 \\
\cline { 2 - 3 } & $q_{e}\left(\mathrm{mg} \mathrm{g}^{-1}\right)$ & 103,5 \\
\cline { 2 - 3 } & $R^{2}$ & 0,97 \\
\hline \multirow{2}{*}{$\begin{array}{c}\text { Pseudo-drugog } \\
\text { reda }\end{array}$} & $k_{2}\left(\mathrm{~g} \mathrm{mg}^{-1} \mathrm{~min}^{-1}\right)$ & 0,02 \\
\cline { 2 - 3 } & $q_{e}\left(\mathrm{mg} \mathrm{g}^{-1}\right)$ & 144,7 \\
\cline { 2 - 3 } & $R^{2}$ & 1,00 \\
\hline
\end{tabular}

Matematičko-kinetički model pseudo-prvog reda nije pogodan za opisivanje adsorpcionog uklanjanja organskih supstanci iz OOSV na nanomaterijalu, jer se ne slažu vrednosti ravnotežnog adsorpcionog kapaciteta: teorijska (138,5 $\left.\mathrm{mg} \mathrm{g} \mathrm{g}^{-1}\right)$ i eksperimentalna (103,5 $\left.\mathrm{mg} \mathrm{g}^{-1}\right)$. Navedene vrednosti se razlikuju 25,3\% u korist teorijske vrednosti (tabela 2). Koeficijent determinacije $\left(R^{2}=0,97\right)$, koji predstavlja meru slaganja eksperimentalnih podataka sa primenjenim kinetičkim modelom adsorpcije, je zadovoljavajući, odnosno veći od 0,95 [6].

Mehanizma adsorpcije organskih supstanci iz OOSV na nanomaterijalu opisuje matematičko-kinetički model pseudo-drugog reda jer su bliske teorijska $\left(138,5 \mathrm{mg} \mathrm{g}^{-1}\right) \mathrm{i}$ eksperimentalna $\left(144,7 \mathrm{mg} \mathrm{g}^{-1}\right)$ vrednost ravnotežnog adsorpcionog kapaciteta. Takođe, i idealna vrednost koeficijenta korelacije pravolinijske zavisnosti $\mathrm{t} / \mathrm{q}_{\mathrm{t}}=f(\mathrm{t})$ $\left(R^{2}=1,00\right)$, potvrđuje validnost modela pseudo-drugog reda (tabela 2). Dobijeni rezultati pokazuju da se organske supstance iz OOSV hemijskim vezama vezuju na površinu nanomaterijala.

\section{ZAKLJUČCI}

Grafički ofset industrijski efluent prema zbirnom kvalitativnom GC/MS profilu organskog opterećenja sadrži 51. organsko jedinjenje sa verovatnoćom prisustva većom od $80 \%$ primenom AMDIS softvera za identifikaciju organskih supstanci i NIST referentne baze podataka. Detektovana organska jedinjenja pripadaju sledećim klasama: višim alkanima, alkenima, policikličnim aromatičnim ugljovodonicima, alkoholima, etrima, ketonima, supstituisanim benzenima i derivatima benzena, organskim kiselinama $i$ njihovim amidima i estrima, organoazotnim jedinjenjima $i$ organskim jedinjenjima sa azotom i kiseonikom. Takođe, prema kvantitativnoj analizi OOSV, koncentracija organskih supstanci (izražena preko UOU) iznosi $2700 \mathrm{mg} \mathrm{L}^{-1}$.

Rezultati adsorpcionog tretmana ofset efluenta pokazuju da sa povećavanjem vremena kontakta adsorbenta (nanomaterijala) i adsorbata (OOSV) raste i efikasnost uklanjanja organskih supstanci iz ofset efluenta. Takođe, sa povećavanjem doze nanomaterijala od 0,5 do $2,5 \mathrm{~g} \mathrm{~L}^{-1}$ efikasnosti se povećavaju od 31 do $62 \%$, redom. Takođe, za sve doze utvrđeno je ravnotežno vreme adsorpcije od 360 minuta. Zbog bliskosti vrednosti efikasnosti uklanjanja UOU za doze nanomaterijala od 1,5 i $2,5 \mathrm{~g} \mathrm{~L}^{-1}(61 \mathrm{i}$ $62 \%$ ) iz ekonomskih razloga uzima se doza od $1,5 \mathrm{~g} \mathrm{~L}^{-1}$.
Za optimalnu dozu od 1,5 $\mathrm{g} \mathrm{L}^{-1}$ efikasnosti uklanjanja UOU iz OOSV sa povećavanjem vremena kontakta adsorbat/adsorbent rastu $\mathrm{u}$ nizu od 11,9 do 55,6\%. Takođe, iz ekonomskih razloga opravdano je za optimalno vreme adsorpcije uzeti 45 minuta, jer se za još 15 i 45 minuta efikasnosti povećavaju 3,4 i 6,5\%, redom.

Nažalost i nakon adsorpcionog tretmana sa optimalnom dozom i ravnotežnim vremenom vrednost UOU 120 puta prelazi granične vrednosti emisije $\left(10 \mathrm{mg} \mathrm{L}^{-1}\right)$ pre mešanja sa ostalim otpadnim vodama. Kako granična vrednost emisije za tehnološke otpadne vode, pre njihovog ispuštanja u javnu kanalizaciju prema Uredbama Republike Srbije nije definisana, zaključuje se da ni tretirano OOSV ne sme da se odlaže u kanalizacioni sistem i prirodni recipijent.

Za određivanje mehanizama adsorpcije organskih supstanci iz OOSV sa nanomaterijalom primenjeni su matematičko-kinetički modeli adsorpcije pseudo-prvog i pseudo-drugog reda. Iako je koeficijent determinacije zadovoljavajući $\left(R^{2}=0,97\right)$, nazalost matematičkokinetički model pseudo-prvog reda nije pogodan za opisivanje mehanizma adsorpcionog uklanjanja organskih supstanci iz OOSV na nanomaterijalu jer se teorijska i eksperimentalna vrednost ravnotežnog adsorpcionog kapaciteta ne slažu.

Organske supstance iz OOSV se hemijskim vezama vezuju na površinu nanomaterijala što je potvrđeno matematičko-kinetičkim modelom pseudo-drugog reda čije su teorijska i eksperimentalna vrednost ravnotežnog adsorpcionog kapaciteta bliske. Opravdanost modela pseudodrugog reda potvrđuje i idealna vrednost koeficijenta determinacije $(1,00)$.

\section{LITERATURA}

[1] S. Adamović, "Elektrokoagulacioni $i$ adsorpcioni tretmani efluenata u grafičkim procesima ofset štampe", Novi Sad, Univerzitet u Novom Sadu, Fakultet tehničkih nauka, 2016.

[2] H. Kipphan, "Handbook of print media: technologies and production methods", Berlin, Springer, 2001.

[3]

https://www.grid.uns.ac.rs/predmet2.html?predmet $=6$ 6 (Pristupljeno u julu 2021.).

[4] SRPS ISO 8245 Metod (2007): Kvalitet vode Smernice za određivanje ukupnog organskog ugljenika (TOC) i rastvorenog organskog ugljenika (DOC).

[5] M. Kragulj, J. Tričković, B. Dalmacija, Á.,Kukovecz, Z. Kónya, J. Molnar, S. Rončević, "Molecular interactions between organic compounds and functionally modified multiwalled carbon nanotubes", Chem. Eng. J., Vol. 225, pp. 144-152, 2013.

[6] A.T. Ivanović, B.T. Trumić, S.Lj. Ivanov, S.P. Marjanović, "Modelovanje uticaja temperature I vremena homogenizacionog žarenja na tvrdoću PdNi5 legure”, Hem. Ind., Vol. 68, pp. 597-603, 2014.

\section{Adrese autora za kontakt:}

Katarina Savić - nina.savic.sm@gmail.com doc. dr Savka Adamović - adamovicsavka@uns.ac.rs Grafičko inženjerstvo i dizajn, FTN, UNS. 